\title{
Temporal inversion of the acid-base equilibrium in newborns: an observational study
}

\author{
Yuko Mizutani ${ }^{1}$, Masahiro Kinoshita ${ }^{2}$, Yung-Chieh Lin ${ }^{3}$, Satoko Fukaya ${ }^{1}$, Shin Kato ${ }^{1}$, Tadashi Hisano ${ }^{1}$, Hideki \\ Hida $^{4}$, Sachiko Iwata ${ }^{1}$, Shinji Saitoh ${ }^{1}$, Osuke Iwata ${ }^{\text {Corresp. } 1}$ \\ ${ }^{1}$ Department of Pediatrics and Neonatology, Nagoya City University Graduate School of Medical Sciences, Nagoya, Aichi, Japan \\ Department of Paediatrics and Child Health, Kurume University School of Medicine, Kurume, Fukuoka, Japan \\ 3 Department of Pediatrics, National Cheng-Kung University, Tainan, Taiwan \\ 4 Department of Neurophysiology and Brain Science, Nagoya City University Graduate School of Medicine, Nagoya City University Graduate School of \\ Medicine, Nagoya, Aichi, Japan \\ Corresponding Author: Osuke Iwata \\ Email address: o.iwata@med.nagoya-cu.ac.jp
}

Background: A considerable fraction of newborn infants experience hypoxia-ischaemia and metabolic acidosis at birth. However, little is known regarding the biological response of newborn infants to the $\mathrm{pH}$ drift from the physiological equilibrium. The aim of this study was to investigate the relationship between the $\mathrm{pH}$ drift at birth and postnatal acid-base regulation in newborn infants.Methods: Clinical information of 200 spontaneously breathing newborn infants hospitalised at a neonatal intensive care centre were reviewed.

Clinical variables associated with venous blood pH on days 5-7 were assessed.Results: The higher blood pH on days 5-7 were explained by lower cord blood pH $(-0.131,-0.210$ to -0.052 ; regression coefficient, $95 \%$ confidence interval), greater gestational age $(0.004$, 0.002 to 0.005$)$ and lower partial pressure of carbon dioxide on days $5-7(-0.005,-0.006$ to -0.004) (adjusted for sex, postnatal age and lactate on days 5-7).Conclusion: In relatively stable newborn infants, blood $\mathrm{pH}$ drift from the physiological equilibrium at birth might trigger a system, which reverts and over-corrects blood $\mathrm{pH}$ within the first week of life. Given that the infants within the study cohort was spontaneously breathing, the observed phenomenon might be a common reaction of newborn infants to $\mathrm{pH}$ changes at birth. 


\section{Temporal inversion of the acid-base equilibrium in}

\section{2 newborns: an observational study}

3

4 Yuko Mizutani ${ }^{1}$, Masahiro Kinoshita ${ }^{2}$, Yung-Chieh Lin $^{3}$, Satoko Fukaya ${ }^{1}$, Shin Kato ${ }^{1}$, Tadashi

5 Hisano $^{1}$, Hideki Hida ${ }^{4}$, Sachiko Iwata ${ }^{1}$, Shinji Saitoh ${ }^{1}$ and Osuke Iwata ${ }^{1}$

6

$7 \quad{ }^{1}$ Center for Human Development and Family Science, Department of Pediatrics and

8 Neonatology, Nagoya City University Graduate School of Medical Sciences, Aichi, Japan.

$9 \quad{ }^{2}$ Centre for Developmental and Cognitive Neuroscience, Department of Paediatrics and Child

10 Health, Kurume University School of Medicine, Fukuoka, Japan.

$11{ }^{3}$ Department of Pediatrics, National Cheng Kung University Hospital, College of Medicine,

12 National Cheng-Kung University, Tainan, Taiwan.

$13{ }^{4}$ Department of Neurophysiology and Brain Science, Nagoya City University Graduate School

14 of Medicine, Aichi, Japan.

16 Corresponding Author:

17 Dr Osuke Iwata,

18 Center for Human Development and Family Science

19 Department of Pediatrics and Neonatology

20 Nagoya City University Graduate School of Medical Sciences

21 Aichi, Nagoya 467-8601, Japan

22 Email address: o.iwata@med.nagoya-cu.ac.jp 


\section{Abstract}

25 Background: A considerable fraction of newborn infants experience hypoxia-ischaemia and 26 metabolic acidosis at birth. However, little is known regarding the biological response of

27 newborn infants to the $\mathrm{pH}$ drift from the physiological equilibrium. The aim of this study was to 28 investigate the relationship between the $\mathrm{pH}$ drift at birth and postnatal acid-base regulation in 29 newborn infants.

30 Methods: Clinical information of 200 spontaneously breathing newborn infants hospitalised at a 31 neonatal intensive care centre were reviewed. Clinical variables associated with venous blood $\mathrm{pH}$ 32 on days 5-7 were assessed.

33 Results: The higher blood $\mathrm{pH}$ on days 5-7 were explained by lower cord blood $\mathrm{pH}(-0.131$, -

340.210 to -0.052 ; regression coefficient, $95 \%$ confidence interval), greater gestational age $(0.004$, 350.002 to 0.005$)$ and lower partial pressure of carbon dioxide on days $5-7(-0.005,-0.006$ to 36 0.004) (adjusted for sex, postnatal age and lactate on days 5-7).

37 Conclusion: In relatively stable newborn infants, blood $\mathrm{pH}$ drift from the physiological equilibrium at birth might trigger a system, which reverts and over-corrects blood $\mathrm{pH}$ within the first week of life. Given that the infants within the study cohort was spontaneously breathing, the observed phenomenon might be a common reaction of newborn infants to $\mathrm{pH}$ changes at birth. 


\section{Introduction}

43 The blood $\mathrm{pH}$ equilibrium is persistently controlled within a narrow range via innate buffers

44 and respiratory and renal systems, and is essential in maintaining regular metabolism in human

45 organs (Pocock $\mathrm{G}$ et al. 2017). These systems also play important roles when the body experiences an acute derangement of the $\mathrm{pH}$ homoeostasis. Adults may encounter severe acute

47 acidosis on limited occasions at critical events (Jung et al. 2011). In contrast, virtually all

48 newborn infants experience some form of hypoxia-ischaemia and acidosis due to disruption of

49 the placental oxygen supply before the establishment of spontaneous breathing (Gleason CA \&

50 Juul SE 2018). Severe birth asphyxia causes critical energy depletion and profound

51 acidosis,(Novak et al. 2018) ultimately leading to critical events, such as hypoxic-ischaemic

52 encephalopathy (Douglas-Escobar \& Weiss 2015). Relatively less severe perinatal stress may

53 also cause serious neurological consequences. Periventricular leukomalacia is a milder form of

54 cerebral injury in preterm infants,(Stoll et al. 2015) the incidence of which increases with the

55 presence of both spontaneous and induced hypocarbia (Okumura et al. 2001; Stenzel et al. 2020).

56 A study from a large-scale cohort suggested that newborn infants who transiently required

57 respiratory support at birth, but did not require hospitalisation, are at increased risk of developing

58 adverse neurodevelopmental outcomes (Odd et al. 2009). Studies in vivo reported increased

59 fraction of apoptotic neuronal death when cultured neurons were transiently exposed to hypoxic-

60 ischaemic environment, and then, to alkalotic environment with sufficient oxygen and energy

61 substrates (Robertson et al. 2013; Vornov et al. 1996). Although these studies highlight the

62 importance of understanding the biological response to the covert disruption of the $\mathrm{pH}$

63 homeostasis at birth, there currently is limited knowledge regarding foetal and neonatal reactions

64 to the $\mathrm{pH}$ drift. The elucidation of such reactions and their association with the injury cascade 
65 may contribute to the development of novel strategies for the early screening, diagnosis and

66 treatment of transition failure at birth and subsequent neurodevelopmental impairments.

68 We performed a retrospective observational study to test a hypothesis that the $\mathrm{pH}$ equilibrium at

69 birth influences acid-base regulation within the first week of life in spontaneously breathing 70 newborn infants.

\section{Materials \& Methods}

\section{Ethics approval and consent}

74 This study was approved by the ethics committee of the Kurume University School of

75 Medicine (H14218). The parental consent for the use of the data was not obtained since no

76 patient identifiers were used.

77

\section{Study population}

Between December 2012 and December 2015, 830 newborn infants were admitted to the neonatal intensive care unit (NICU) of Kurume University Hospital, which is a tertiary referral centre. Of these, we reviewed the clinical records of 200 newborn infants (mean \pm standard deviation, $36.9 \pm 1.7$ weeks gestation and $2453 \pm 735 \mathrm{~g}$ at birth), excluding 630 infants, who did not undergo blood gas analysis at birth or on days 5-7, who were still mechanically ventilated on

84 day 7 and who were given sodium bicarbonate by day 7 ( $n=52,472,102$ and 4, respectively; 85 Figure 1).

86

\section{Sample collection}


88 In this unit, routine blood gas analysis is performed (i) at birth (umbilical venous samples), (ii)

89 on day 0 (venous samples typically obtained shortly after admission), on day 3 (venous/capillary

90 samples) and between days 5 and 7 (venous/capillary samples obtained at the time of the

91 newborn screening test). Blood gas analysis on days 5-7 is not performed for infants who have

92 been discharged home or moved to the step-down unit. The blood $\mathrm{pH}$; partial pressures of carbon

93 dioxide $\left(\mathrm{pCO}_{2}\right)$ and oxygen; bicarbonate $\left(\mathrm{HCO}_{3}^{-}\right)$; sodium; potassium; calcium; chloride; lactate;

94 glucose; total, carboxyl and foetal haemoglobin; and total bilirubin levels are simultaneously

95 measured (ABL800; Radiometer, Copenhagen, Denmark). However, for cord blood samples,

96 only the $\mathrm{pH}$ was available from the electronic record. Blood gas data from all routine and

97 additional blood tests performed within 24 hours of birth and between 5 and 7 days of birth were

98 incorporated.

\section{Clinical variables}

101 Clinical information was collected from the patient records, including the maternal

102 complication, gestational age, birth weight (z-scores also calculated against the standard birth

103 weight (Itabashi et al. 2014)), sex, delivery mode, Apgar scores, use of an intravenous sodium

104 bicarbonate injection and duration of positive pressure ventilation.

\section{Data analysis}

107 To highlight the selection bias, clinical backgrounds were compared between the infants within

108 the final study cohort and those, who were excluded, using the Student's t-test, Mann-Whitney's

$109 \mathrm{U}$ test or chi-square test. To assess temporal changes in blood $\mathrm{pH}$ after birth, relationships

110 between cord blood $\mathrm{pH}$ and blood $\mathrm{pH}$ on days 5-7 were assessed adjusting for clinical 
111 backgrounds and priori covariates; blood samples obtained later than day 7 were not considered

112 because of the selection bias derived from non-routine sampling of these samples. A generalised

113 estimating equation was used to correct for repeated sampling and postnatal age at blood

114 sampling (SPSS version 25; IBM, Armonk, NY, USA). Findings from the univariate analysis

115 were not corrected for multiple comparisons; however, p-values between 0.01 and 0.05 were

116 regarded as "chance level". To evaluate the potential influence of respiratory support on the

117 relationship between cord blood $\mathrm{pH}$ and blood $\mathrm{pH}$ on days $5-7$, the univariate analysis was

118 repeated in (i) a restrictive population of infants, who never experienced invasive respiratory

119 support $(\mathrm{n}=157)$ and (ii) an expanded population of the final study cohort and those, who

120 remained intubated at the time of blood sampling on days 5-7 $(\mathrm{n}=302$ in total).

121 A multivariate model to explain the blood $\mathrm{pH}$ on days 5-7 was then developed for the final

122 study cohort. First, the relationship between cord blood $\mathrm{pH}$ and blood $\mathrm{pH}$ on days 5-7 was

123 assessed adjusting for sex and postnatal age. The influence of gestational age at birth and $\mathrm{pCO}_{2}$

124 and lactate levels on days 5-7 was assessed using the forward stepwise selection algorithm.

125 Values are presented as mean \pm standard deviation, median [interquartile range] or number $(\%)$

126 unless otherwise specified.

127

\section{Results}

129 Compared with the 200 infants within the final study cohort, the 630 infants, who were 130 excluded from the analysis, had smaller birth weight $(\mathrm{p}=0.008)$ but statistically invariant

131 gestational age at birth, Z-score of the birth weight, cord blood pH, 1- and 5-min Apgar scores

132 and rates of female sex, chorioamnionitis, intubation on day 0 , non-invasive positive pressure

133 ventilation on day 0 and non-invasive positive pressure ventilation on days 5-7 (Table 1 and 
134 Supplemental Information 1). The primary indications for NICU admission for the study

135 population were preterm birth, low-birth-weight, respiratory problems, congenital anomalies,

136 infectious diseases, birth asphyxia, gastro-intestinal diseases, jaundice, birth trauma, other

137 reasons $(\mathrm{n}=75,35,20,20,9,4,4,3,1$ and 5, respectively) and maternal reasons (thyroid

138 diseases, diabetes, anti-Ro/SSA autoantibodies and immune thrombocytopaenic purpura; $\mathrm{n}=10$,

1395,5 and 4, respectively). A total of 157 infants never experienced invasive mechanical

140 ventilation, whereas 43 infants were initially intubated but had been extubated by the time of

141 blood sampling on days 5-7 (78.5\% and 21.5\%, respectively; Figure 1). Non-invasive positive

142 airway pressure ventilation was used in 27 infants on day 0 and in 17 infants at the time of blood

143 sampling on days 5-7. On days 0 and 5-7, 453 and 249 samples were analysed, respectively

144 (Table 1).

145 Univariate analysis showed that a higher blood $\mathrm{pH}$ on days 5-7 was associated with a greater

146 gestational age; heavier birth weight; lower cord blood $\mathrm{pH}$; higher lactate, higher glucose, higher

147 anion gap, lower carboxyl haemoglobin and lower foetal haemoglobin levels on day 0; and lower

$148 \mathrm{pCO}_{2}$, lower calcium, lower chloride and higher $\mathrm{HCO}_{3}^{-}$levels on days 5-7 $(\mathrm{p}<0.001, \mathrm{p}<0.001$,

$149 \mathrm{p}<0.001, \mathrm{p}<0.001, \mathrm{p}=0.010, \mathrm{p}=0.001, \mathrm{p}=0.001, \mathrm{p}<0.001, \mathrm{p}<0.001, \mathrm{p}<0.001, \mathrm{p}=0.001$

150 and $\mathrm{p}=0.002$, respectively; Table 2 and Online Supplemental Information 2). The relationship

151 between cord blood $\mathrm{pH}$ and blood $\mathrm{pH}$ on days 5-7 was consistently observed in both subcohorts

152 of infants, who never experienced invasive respiratory support (regression coefficient, -0.154 ;

$15395 \%$ confidence interval, $-0.258--0.050 ; \mathrm{p}=0.004)$ and expanded study population including

154 those, who remained intubated at the time of blood sampling on days 5-7 (regression coefficient,

$155-0.115 ; 95 \%$ confidence interval, $-0.165--0.065 ; \mathrm{p}<0.001)$ (Online Supplemental Information

1563 and 4).

Peer) reviewing PDF | (2020:10:54161:1:0:NEW 22 Feb 2021) 
158 The first multivariate model (Model 1) was adjusted for the postnatal age and sex, which 159 showed a negative relationship between the cord blood $\mathrm{pH}$ and blood $\mathrm{pH}$ on days 5-7 ( $\mathrm{p}<0.001$, 160 Table 3). Model 2 included the variables in Model 1 and gestational age, whereas Model 3 161 included the variables in Model 2 plus $\mathrm{pCO}_{2}$ on days 5-7, both of which supported the 162 relationship between the cord blood $\mathrm{pH}$ and blood $\mathrm{pH}$ on days 5-7 ( $\mathrm{p}=0.005$ and $\mathrm{p}<0.001$, 163 respectively; Table 3). The final model (Model 4) was adjusted for the same variables as Model 1643 plus the lactate level on days 5-7, where lower cord blood $\mathrm{pH}$, greater gestational age and 165 lower $\mathrm{pCO}_{2}$ levels on days 5-7 (regression coefficient: $-0.131,0.004$ and $-0.005 ; 95 \%$ confidence 166 interval : -0.210 to $-0.052,0.002$ to 0.005 and -0.006 to -0.004 ; and $\mathrm{p}=0.001, \mathrm{p}<0.001$ and $\mathrm{p}<$ 167 0.001, respectively) explained the higher venous blood $\mathrm{pH}$ on days 5-7 (Table 3). To identify the 168 intermediate variable explaining the relationship between the cord blood $\mathrm{pH}$ and blood $\mathrm{pH}$ on 169 days 5-7, Model 5 was additionally adjusted for the covariates in Model 4 plus $\mathrm{HCO}_{3}^{-}$on days 5 1707 , where the role of cord blood $\mathrm{pH}$ as an independent variable for blood $\mathrm{pH}$ on days 5-7 was 171 replaced by $\mathrm{HCO}_{3}{ }^{-}$on days $5-7(\mathrm{p}<0.001$, Table 3)

\section{Discussion}

174 In spontaneously breathing newborn infants, a higher blood $\mathrm{pH}$ on days 5-7 was paradoxically 175 related to a lower cord blood $\mathrm{pH}$. Considering that the $\mathrm{pH}$ equilibrium of these infants was likely 176 to be determined by their own spontaneous regulation, this temporal inversion of the blood $\mathrm{pH}$

177 homeostasis within the first week of life might represent a physiological response in newborn 178 infants to the drift in the $\mathrm{pH}$ equilibrium at birth. 
180 In our current study, higher blood pH levels on days 5-7 were best explained by the cord blood $181 \mathrm{pH}$, as well as gestational age, $\mathrm{pCO}_{2}$ and lactate levels of the same blood sample obtained on 182 days 5-7. Considering that the role of the cord blood $\mathrm{pH}$ as an independent variable for the blood $183 \mathrm{pH}$ on days 5-7 was superseded by $\mathrm{HCO}_{3}^{-}$levels on days 5-7, it would be relevant to speculate 184 that the $\mathrm{pH}$ drift in the cord blood towards an acidic (alkalotic) equilibrium triggered the active 185 accumulation (elimination) of blood $\mathrm{HCO}_{3}{ }^{-}$to temporally invert the acid-base homeostasis 186 within the first week of life. Although our study cohort did not include those with severe birth 187 asphyxia or excessive immaturity and all of the infants who were included had been weaned 188 from mechanical ventilation by the time of blood gas analysis on days 5-7, even transient resuscitation and mechanical ventilation may well influence the acid-base regulation thereafter. However, the relationship between cord blood $\mathrm{pH}$ and blood $\mathrm{pH}$ on days 5-7 was consistently observed in both restrictive (those who never experienced invasive respiratory support) and expanded (the original cohort plus those who remained intubated at the time of blood sampling on days 5-7) study populations, suggesting that the influence of the respiratory support on the temporal change of the blood $\mathrm{pH}$ may be limited. Provided that the blood $\mathrm{pH}$ equilibrium of these infants was determined as a consequence of spontaneous acid-base control, the negative relationship between the cord blood $\mathrm{pH}$ and the blood $\mathrm{pH}$ on days 5-7 might be a physiological

197 response in newborn infants. haemoglobin, which help eliminate carbon dioxide via the placenta (Blechner 1993). After birth, 201 the role of the placenta in maintaining the acid-base homeostasis is replaced by the lung and 202 proximal tubule of the kidney, which, together with the innate buffering system, contribute to 
203 ameliorate acidosis. Proton transporters, such as the $\mathrm{Na}^{+} / \mathrm{H}^{+}$exchanger and proton ATPase, play

204 a central role in the $\mathrm{pH}$ homeostasis by the proximal tubule (Hamm et al. 2015; Pirojsakul et al.

205 2015). The $\mathrm{Na}^{+} / \mathrm{H}^{+}$exchanger is also involved in the maintenance of the intracellular $\mathrm{pH}$ and cell

206 volume in a range of cell types (Uria-Avellanal \& Robertson 2014). Severe birth asphyxia

207 triggers anaerobic glycolysis, leading to the accumulation of lactate within the intracellular fluid

208 (Rainaldi \& Perlman 2016). The acidic shift of the intracellular fluid activates the function of the

$209 \mathrm{Na}^{+} / \mathrm{H}^{+}$exchanger. Interestingly, once this transporter is activated by severe hypoxia-ischaemia,

210 elimination of intracellular protons persists even after the intracellular $\mathrm{pH}$ is normalised, leading

211 to an intracellular alkaline overshoot, or a $\mathrm{pH}$ paradox, in the neuronal tissue of asphyxiated

212 newborn species (Kendall et al. 2006; Robertson et al. 2005; Robertson et al. 2002; Uria-

213 Avellanal \& Robertson 2014). The $\mathrm{pH}$ paradox appears to be relevant as a homeostatic reaction

214 to acidosis. However, this phenomenon is simultaneously linked to cell death and severe tissue

215 injury, rather than survival (Robertson et al. 2002; Uria-Avellanal \& Robertson 2014). A similar

216 phenomenon to the $\mathrm{pH}$ paradox has been observed in the $\mathrm{pH}$ control of the extracellular fluid.

217 Helmly et al. showed that during the recovery phase from hypoxia-ischaemia, the seizure burden

218 is tightly linked with an alkaline overshoot recovery of the extracellular pH (Helmy et al. 2012).

219 These findings suggest that an alkaline overshoot of the intracellular and extracellular fluids

220 within the cerebral tissue might be a common consequence of severe acidosis and may play an

221 important role in the progression of cerebral injury. Although we did not assess $\mathrm{pH}$ levels of the

222 cerebral tissue and cerebrospinal fluid, a similar reaction to the $\mathrm{pH}$ paradox might exist for the

223 tubular $\mathrm{Na}^{+} / \mathrm{H}^{+}$exchanger (Ibrahim et al. 2008; Twombley et al. 2010), which might be activated

224 to correct and reverse the blood $\mathrm{pH}$ equilibrium in response to even a mild acidic drift in the

225 blood at birth. 
226 An alternative explanation is possible from the spontaneous down-regulation of energy

227 metabolism and thermogenesis following severe hypoxia-ischaemia, observed in a range of

228 vertebrates (Wood \& Gonzales 1996; Wood et al. 2018). Downregulation of energy metabolism

229 may cause an alkaline shift in the $\mathrm{pH}$ equilibrium via reduced production of carbon dioxide and

230 lactate. Indeed, an alkaline shift in the blood $\mathrm{pH}$ has been observed in newborn infants who were

231 managed with therapeutic hypothermia, although most of these findings are accompanied by

232 reduced blood carbon dioxide levels (Pappas et al. 2011; Szakmar et al. 2018; Thoresen 2008).

233

234 Several limitations in the current study need to be addressed. First, the $\mathrm{pCO}_{2}, \mathrm{HCO}_{3}{ }^{-}$and lactate

235 levels were not available from the cord blood gas analysis, leading to uncertainty in which type

236 of $\mathrm{pH}$ drift at birth triggered the inversion of $\mathrm{pH}$ homeostasis thereafter. Second, as previously

237 described, our study cohort was of NICU infants. Although it is ethically unacceptable to

238 perform serial blood sampling in healthy newborn infants, our findings need to be reassessed in a

239 term-born cohort with relatively more mature tubular and respiratory functions, acid-base

240 regulation system and homogeneous clinical backgrounds. Finally, because our current findings

241 are not similar to previously reported phenomena in the clinical setting, the proposed

242 explanations of the temporal inversion of $\mathrm{pH}$ equilibrium after birth are only speculative, and the

243 precise mechanism needs to be elucidated by future studies.

244

\section{Conclusions}

246 An acidic shift in the blood $\mathrm{pH}$ at birth led to an increase in the bicarbonate and blood $\mathrm{pH}$ on 247 days 5-7 in spontaneously breathing NICU infants. To our knowledge, this is the first study to 248 report a temporal inversion of the blood $\mathrm{pH}$ within the first week of life. Further investigation of 
249 this phenomenon may help reveal a novel injury cascade and physiological response to the $\mathrm{pH}$ 250 drift at birth in newborn infants.

251 
252

253

254

255

256

257

258

259

260

261

262

263

264

265

266

267

268

269

270

271

272

273

274

275

276

277

278

279

280

281

282

283

284

285

286

287

288

289

290

291

292

293

294

295

\section{References}

Blechner JN. 1993. Maternal-fetal acid-base physiology. Clin Obstet Gynecol 36:3-12. 10.1097/00003081-199303000-00004

Douglas-Escobar M, and Weiss MD. 2015. Hypoxic-ischemic encephalopathy: a review for the clinician. JAMA Pediatr 169:397-403. 10.1001/jamapediatrics.2014.3269

Gleason CA, and Juul SE. 2018. Avery's Diseases of the Newborn 10th Edition. Philadelphia, United States of America: Elsevier.

Hamm LL, Nakhoul N, and Hering-Smith KS. 2015. Acid-Base Homeostasis. Clin J Am Soc Nephrol 10:2232-2242. 10.2215/cjn.07400715

Helmy MM, Ruusuvuori E, Watkins PV, Voipio J, Kanold PO, and Kaila K. 2012. Acid extrusion via blood-brain barrier causes brain alkalosis and seizures after neonatal asphyxia. Brain 135:3311-3319. 10.1093/brain/aws257

Ibrahim H, Lee YJ, and Curthoys NP. 2008. Renal response to metabolic acidosis: role of mRNA stabilization. Kidney Int 73:11-18. 10.1038/sj.ki.5002581

Itabashi K, Miura F, Uehara R, and Nakamura Y. 2014. New Japanese neonatal anthropometric charts for gestational age at birth. Pediatr Int 56:702-708. 10.1111/ped.12331

Jung B, Rimmele T, Le Goff C, Chanques G, Corne P, Jonquet O, Muller L, Lefrant JY, Guervilly C, Papazian L, Allaouchiche B, and Jaber S. 2011. Severe metabolic or mixed acidemia on intensive care unit admission: incidence, prognosis and administration of buffer therapy. A prospective, multiple-center study. Crit Care 15:R238. 10.1186/cc10487

Kendall GS, Robertson NJ, Iwata O, Peebles D, and Raivich G. 2006. N-methylisobutyl-amiloride ameliorates brain injury when commenced before hypoxia ischemia in neonatal mice. Pediatr Res 59:227-231. 10.1203/01.pdr.0000196805.68082.22

Novak CM, Ozen M, and Burd I. 2018. Perinatal Brain Injury: Mechanisms, Prevention, and Outcomes. Clin Perinatol 45:357-375. 10.1016/j.clp.2018.01.015

Odd DE, Lewis G, Whitelaw A, and Gunnell D. 2009. Resuscitation at birth and cognition at 8 years of age: a cohort study. Lancet 373:1615-1622. 10.1016/s0140-6736(09)60244-0

Okumura A, Hayakawa F, Kato T, Itomi K, Maruyama K, Ishihara N, Kubota T, Suzuki M, Sato Y, Kuno K, and Watanabe K. 2001. Hypocarbia in preterm infants with periventricular leukomalacia: the relation between hypocarbia and mechanical ventilation. Pediatrics 107:469-475. 10.1542/peds.107.3.469

Pappas A, Shankaran S, Laptook AR, Langer JC, Bara R, Ehrenkranz RA, Goldberg RN, Das A, Higgins RD, Tyson JE, and Walsh MC. 2011. Hypocarbia and adverse outcome in neonatal hypoxic-ischemic encephalopathy. $J$ Pediatr 158:752-758.e751. 10.1016/j.jpeds.2010.10.019

Pirojsakul K, Gattineni J, Dwarakanath V, and Baum M. 2015. Renal NHE expression and activity in neonatal NHE3- and NHE8-null mice. Am J Physiol Renal Physiol 308:F31-38. 10.1152/ajprenal.00492.2014

Pocock G, Richards CD, and Richards DA. 2017. Human Physiology Fifth Edition. New York, United States of America: Oxford University Press. 
296

297

298

299

300

301

302

303

304

305

306

307

308

309

310

311

312

313

314

315

316

317

318

319

320

321

322

323

324

325

326

327

328

329

330

331

332

333

334

335

336

337

338

339

340

Rainaldi MA, and Perlman JM. 2016. Pathophysiology of Birth Asphyxia. Clin Perinatol 43:409-422. 10.1016/j.clp.2016.04.002

Robertson NJ, Bhakoo K, Puri BK, Edwards AD, and Cox IJ. 2005. Hypothermia and amiloride preserve energetics in a neonatal brain slice model. Pediatr Res 58:288-296. 10.1203/01.Pdr.0000170899.90479.1e

Robertson NJ, Cowan FM, Cox IJ, and Edwards AD. 2002. Brain alkaline intracellular $\mathrm{pH}$ after neonatal encephalopathy. Ann Neurol 52:732-742. 10.1002/ana.10365

Robertson NJ, Kato T, Bainbridge A, Chandrasekaran M, Iwata O, Kapetanakis A, Faulkner S, Cheong J, Iwata S, Hristova M, Cady E, and Raivich G. 2013. Methyl-isobutyl amiloride reduces brain Lac/NAA, cell death and microglial activation in a perinatal asphyxia model. $J$ Neurochem 124:645-657.

10.1111/jnc. 12097

Stenzel M, Stüwe-Kunz L, Bührer C, and Roll C. 2020. Spontaneous hypocarbia without mechanical ventilation in preterm infants with cystic periventricular leukomalacia. Acta Paediatr. 10.1111/apa.15235

Stoll BJ, Hansen NI, Bell EF, Walsh MC, Carlo WA, Shankaran S, Laptook AR, Sánchez PJ, Van Meurs KP, Wyckoff M, Das A, Hale EC, Ball MB, Newman NS, Schibler K, Poindexter BB, Kennedy KA, Cotten CM, Watterberg KL, D'Angio CT, DeMauro SB, Truog WE, Devaskar U, and Higgins RD. 2015. Trends in Care Practices, Morbidity, and Mortality of Extremely Preterm Neonates, 1993-2012. Jama 314:1039-1051. 10.1001/jama.2015.10244

Szakmar E, Kovacs K, Meder U, Bokodi G, Szell A, Somogyvari Z, Szabo AJ, Szabo M, and Jermendy A. 2018. Asphyxiated neonates who received active therapeutic hypothermia during transport had higher rates of hypocapnia than controls. Acta Paediatr 107:1902-1908. 10.1111/apa.14159

Thoresen M. 2008. Supportive care during neuroprotective hypothermia in the term newborn: adverse effects and their prevention. Clin Perinatol 35:749-763, vii. 10.1016/j.clp.2008.07.018

Twombley K, Gattineni J, Bobulescu IA, Dwarakanath V, and Baum M. 2010. Effect of metabolic acidosis on neonatal proximal tubule acidification. Am J Physiol Regul Integr Comp Physiol 299:R1360-1368. 10.1152/ajpregu.00007.2010

Uria-Avellanal C, and Robertson NJ. 2014. $\mathrm{Na}^{+} / \mathrm{H}^{+}$exchangers and intracellular $\mathrm{pH}$ in perinatal brain injury. Trans/ Stroke Res 5:79-98. 10.1007/s12975-013-0322-x

Vornov JJ, Thomas AG, and Jo D. 1996. Protective effects of extracellular acidosis and blockade of sodium/hydrogen ion exchange during recovery from metabolic inhibition in neuronal tissue culture. J Neurochem 67:2379-2389. 10.1046/j.14714159.1996.67062379.x

Wood SC, and Gonzales R. 1996. Hypothermia in hypoxic animals: mechanisms, mediators, and functional significance. Comp Biochem Physiol B Biochem Mol Biol 113:37-43. 10.1016/0305-0491(95)02045-4

Wood T, Hobbs C, Falck M, Brun AC, Løberg EM, and Thoresen M. 2018. Rectal temperature in the first five hours after hypoxia-ischemia critically affects neuropathological outcomes in neonatal rats. Pediatr Res 83:536-544. 10.1038/pr.2017.51

Peer) reviewing PDF | (2020:10:54161:1:0:NEW 22 Feb 2021) 
Figure 1

Flow chart of study population

Total admissions to the neonatal intensive care unit

between December 2012 and December $2015(n=830)$

Excluded: $(\mathrm{n}=630)$

Umbilical cord $\mathrm{pH}$ not analysed $(\mathrm{n}=52)$

Blood gas not analysed on days 5-7 $(\mathrm{n}=472)$

Remained intubated on days 5-7 $(n=102)$

Intravenous sodium bicarbonate prescribed $(n=4)$

Study cohort $(n=200)$ 


\section{Table $\mathbf{1}$ (on next page)}

The background variables of the study population 
1 Table 1: Background variables of the study population.

Variables

Gestational age (weeks)

$36.9 \pm 1.7$

Body weight at birth (g)

$2453 \pm 735$

Z-score of above (-)

$-0.53 \pm 1.47$

Female sex

$88(44 \%)$

1-min Apgar score (-)

8 [7-9]

5-min Apgar score (-)

$9[8-9]$

Caesarean delivery

$96(48 \%)$

Premature rupture of the membranes

$43(22 \%)$

Hypertensive disorders of pregnancy

$14(7 \%)$

Gestational diabetes

$25(13 \%)$

Chorioamnionitis

$23(12 \%)$

Intubation on day 0

$43(22 \%)$

Non-invasive positive pressure ventilation on day 0

$27(14 \%)$

Non-invasive positive pressure ventilation on days $5-7^{*}$

$17(9 \%)$

Cord blood $\mathrm{pH}(-)$

$7.29 \pm 0.09$

Requirement for phototherapy

$89(45 \%)$

Postnatal age at full enteral nutrition $>100 \mathrm{ml} / \mathrm{kg}$ (days)

$4.2 \pm 3.6$

Blood tests on day 0

$$
\begin{aligned}
& \mathrm{pH}(-) \\
& \mathrm{pCO}_{2}(\mathrm{mmHg}) \\
& \mathrm{HCO}_{3}{ }^{-}(\mathrm{mmol} / \mathrm{L}) \\
& \text { Lactate }(\mathrm{mmol} / \mathrm{L}) \\
& \text { Glucose }(\mathrm{mg} / \mathrm{dL}) \\
& \mathrm{Na}^{+}(\mathrm{mmol} / \mathrm{L}) \\
& \mathrm{K}^{+}(\mathrm{mmol} / \mathrm{L}) \\
& \mathrm{Ca}^{2+}(\mathrm{mmol} / \mathrm{L}) \\
& \mathrm{Cl}^{-}(\mathrm{mmol} / \mathrm{L})
\end{aligned}
$$

Anion gap (mmol/L)

$7.30 \pm 0.11$

$48.0 \pm 13.6$

$22.3 \pm 3.3$

$0.42 \pm 0.36$

$86 \pm 47$

$136 \pm 3$

$4.8 \pm 1.0$

$1.26 \pm 0.12$

$106 \pm 4$

$7.4 \pm 5.2$

Total haemoglobin (g/dL)

$17.4 \pm 3.2$

Carboxyl haemoglobin (\%)

$1.4 \pm 0.7$

Foetal haemoglobin (\%)

$77.3 \pm 11.4$

Total bilirubin ( $\mathrm{mg} / \mathrm{dL})$

$2.3 \pm 1.6$

Blood tests on days 5-7

$\mathrm{pH}(-)$

$7.37 \pm 0.05$ 
$\mathrm{pCO}_{2}(\mathrm{mmHg})$

$41.3 \pm 6.4$

$\mathrm{HCO}_{3}{ }^{-}(\mathrm{mmol} / \mathrm{L})$

$23.0 \pm 2.9$

Lactate $(\mathrm{mmol} / \mathrm{L})$

$0.22 \pm 0.09$

Glucose (mg/dL)

$90 \pm 21$

$\mathrm{Na}^{+}(\mathrm{mmol} / \mathrm{L})$

$138 \pm 4$

$\mathrm{K}^{+}(\mathrm{mmol} / \mathrm{L})$

$4.7 \pm 0.8$

$\mathrm{Ca}^{2+}(\mathrm{mmol} / \mathrm{L})$

$1.24 \pm 0.14$

$\mathrm{Cl}^{-}(\mathrm{mmol} / \mathrm{L})$

$108 \pm 5$

$\square$ Anion gap (mmol/L)

$7.6 \pm 2.5$

Total haemoglobin (g/dL)

$16.7 \pm 2.3$

Carboxyl haemoglobin (\%)

$1.2 \pm 0.5$

Foetal haemoglobin (\%)

$73.1 \pm 13.4$

Total bilirubin (mg/dL)

$8.9 \pm 3.5$

Heart rates on day 0 (beats per min)

$135 \pm 13.2$

Respiratory rates on day 0 (breaths per min)

$47.5 \pm 10.2$

Heart rates on days 5-7 (beats per min)

$142.0 \pm 11.1$

Respiratory rates on days 5-7 (breaths per min)

$44.8 \pm 7.5$

2 Values are shown as mean \pm standard deviation, median [interquartile range] or number (\%).

3 *At the time of blood sampling. 
Table 2 (on next page)

Dependence of the blood $\mathrm{pH}$ on days 5-7 on the clinical variables: univariate analysis 
1 Table 2: Dependence of blood pH on days 5-7 on clinical variables: univariate analysis

\begin{tabular}{|c|c|c|c|c|c|}
\hline \multirow{3}{*}{ Variables } & & \multicolumn{3}{|c|}{ Regression coefficient } & \multirow{3}{*}{$p$} \\
\hline & & & \multicolumn{2}{|c|}{$95 \%$ confidence interval } & \\
\hline & & & Lower & Upper & \\
\hline \multicolumn{2}{|l|}{ Gestational age (weeks) } & 0.005 & 0.004 & 0.007 & $<0.001$ \\
\hline \multicolumn{2}{|c|}{$\begin{array}{l}\text { Body weight at birth (per 100g) } \\
\text { Z-score of the above }\end{array}$} & 0.002 & 0.001 & 0.003 & $<0.001$ \\
\hline \multicolumn{2}{|c|}{$\begin{array}{l}\text { Z-score of the above } \\
\text { parameters }\end{array}$} & 0.001 & -0.004 & 0.006 & 0.643 \\
\hline \multicolumn{2}{|l|}{ Female sex } & 0.001 & -0.014 & 0.017 & 0.848 \\
\hline \multicolumn{2}{|l|}{ Cord blood $\mathrm{pH}$} & -0.126 & -0.180 & -0.073 & $<0.001$ \\
\hline \multicolumn{2}{|l|}{ 1-min Apgar score } & 0.002 & -0.005 & 0.005 & 0.879 \\
\hline \multicolumn{2}{|l|}{ 5-min Apgar score } & -0.002 & -0.007 & 0.003 & 0.471 \\
\hline \multirow[t]{15}{*}{ Blood tests on day 0} & Age in hour & -0.001 & -0.001 & 0.001 & 0.850 \\
\hline & $\mathrm{pH}$ & -0.070 & -0.153 & 0.013 & 0.100 \\
\hline & $\mathrm{pCO}_{2}(\mathrm{mmHg})$ & 0.000 & 0.000 & 0.001 & 0.147 \\
\hline & $\mathrm{HCO}_{3}^{-}(\mathrm{mmol} / \mathrm{L})$ & -0.002 & -0.005 & 0.001 & 0.125 \\
\hline & Lactate $(\mathrm{mmol} / \mathrm{L})$ & 0.034 & 0.017 & 0.050 & $<0.001$ \\
\hline & Glucose (mg/dL) & 0.000 & 0.000 & 0.000 & 0.010 \\
\hline & $\mathrm{Na}^{+}(\mathrm{mmol} / \mathrm{L})$ & 0.001 & -0.001 & 0.003 & 0.347 \\
\hline & $\mathrm{K}^{+}(\mathrm{mmol} / \mathrm{L})$ & -0.005 & -0.013 & 0.003 & 0.238 \\
\hline & $\mathrm{Ca}^{2+}(\mathrm{mmol} / \mathrm{L})$ & 0.043 & -0.013 & 0.099 & 0.131 \\
\hline & $\mathrm{Cl}^{-}(\mathrm{mmol} / \mathrm{L})$ & -0.002 & -0.004 & 0.000 & 0.074 \\
\hline & Anion gap $(\mathrm{mmol} / \mathrm{L})$ & 0.002 & 0.007 & 0.004 & 0.001 \\
\hline & Total haemoglobin $(\mathrm{g} / \mathrm{dL})$ & 0.000 & -0.003 & 0.008 & 0.929 \\
\hline & Carboxyl haemoglobin (\%) & -0.018 & -0.029 & -0.008 & 0.001 \\
\hline & Foetal haemoglobin (\%) & -0.001 & -0.002 & -0.001 & $<0.001$ \\
\hline & Total bilirubin $(\mathrm{mg} / \mathrm{dL})$ & -0.002 & -0.007 & 0.002 & 0.330 \\
\hline \multirow[t]{14}{*}{ Blood tests on days 5-7 } & Postnatal age (days) & 0.013 & -0.002 & 0.027 & 0.085 \\
\hline & $\mathrm{pCO}_{2}(\mathrm{mmHg})$ & -0.005 & -0.006 & -0.004 & $<0.001$ \\
\hline & $\mathrm{HCO}_{3}{ }^{-}(\mathrm{mmol} / \mathrm{L})$ & 0.005 & 0.002 & 0.008 & 0.002 \\
\hline & Lactate $(\mathrm{mmol} / \mathrm{L})$ & 0.032 & -0.035 & 0.099 & 0.346 \\
\hline & Glucose (mg/dL) & 0.000 & -0.001 & 0.000 & 0.173 \\
\hline & $\mathrm{Na}^{+}(\mathrm{mmol} / \mathrm{L})$ & 0.000 & -0.003 & 0.002 & 0.754 \\
\hline & $\mathrm{K}^{+}(\mathrm{mmol} / \mathrm{L})$ & -0.001 & -0.011 & 0.009 & 0.847 \\
\hline & $\mathrm{Ca}^{2+}(\mathrm{mmol} / \mathrm{L})$ & -0.098 & -0.152 & -0.044 & $<0.001$ \\
\hline & $\mathrm{Cl}^{-}(\mathrm{mmol} / \mathrm{L})$ & -0.003 & -0.004 & -0.001 & 0.001 \\
\hline & Anion gap $(\mathrm{mmol} / \mathrm{L})$ & 0.002 & -0.001 & 0.005 & 0.120 \\
\hline & Total haemoglobin $(\mathrm{g} / \mathrm{dL})$ & 0.001 & -0.002 & 0.005 & 0.448 \\
\hline & Carboxyl haemoglobin (\%) & 0.015 & -0.030 & 0.033 & 0.110 \\
\hline & Foetal haemoglobin (\%) & 0.000 & -0.001 & 0.000 & 0.163 \\
\hline & Total bilirubin $(\mathrm{mg} / \mathrm{dL})$ & 0.003 & 0.001 & 0.005 & 0.012 \\
\hline \multicolumn{2}{|c|}{ Heart rates on day 0 (beats per min) } & -0.001 & -0.001 & 0.000 & 0.091 \\
\hline \multicolumn{2}{|c|}{ Respiratory rates on day 0 (breaths per min) } & 0.000 & -0.001 & 0.000 & 0.420 \\
\hline \multicolumn{2}{|c|}{ Heart rates on days 5-7 (beats per min) } & -0.001 & -0.002 & 0.000 & 0.071 \\
\hline \multicolumn{2}{|c|}{ Respiratory rates on days 5-7 (breaths per min) } & 0.000 & -0.001 & 0.001 & 0.985 \\
\hline
\end{tabular}


2 Statistical significance was assumed for $p<0.01$ (indicated in bold).

3 


\section{Table $\mathbf{3}$ (on next page)}

Dependence of the blood $\mathrm{pH}$ on days 5-7 on the cord blood $\mathrm{pH}$ : multivariate models 
1 Table 3: Dependence of blood pH on days 5-7 on cord blood pH: multivariate models

\begin{tabular}{|c|c|c|c|c|}
\hline \multirow{3}{*}{ Variables } & \multirow{3}{*}{ Mean } & \multicolumn{2}{|c|}{ Regression coefficient } & \multirow{3}{*}{$p$} \\
\hline & & \multicolumn{2}{|c|}{$95 \%$ confidence interval } & \\
\hline & & Lower & Upper & \\
\hline \multicolumn{5}{|l|}{ Model 1} \\
\hline Cord blood $\mathrm{pH}$ & -0.127 & -0.181 & -0.073 & $<0.001$ \\
\hline Postnatal age (days) & 0.014 & 0.000 & 0.027 & 0.047 \\
\hline Female sex & -0.001 & -0.015 & 0.013 & 0.845 \\
\hline \multicolumn{5}{|l|}{ Model 2} \\
\hline Cord blood $\mathrm{pH}$ & -0.088 & -0.149 & -0.027 & 0.005 \\
\hline Postnatal age (days) & 0.007 & -0.006 & 0.020 & 0.283 \\
\hline Female sex & -0.001 & -0.014 & 0.012 & 0.866 \\
\hline Gestational age (weeks) & 0.005 & 0.003 & 0.006 & $<0.001$ \\
\hline \multicolumn{5}{|l|}{ Model 3} \\
\hline Cord blood $\mathrm{pH}$ & -0.120 & -0.184 & -0.055 & $<0.001$ \\
\hline Postnatal age (days) & -0.001 & -0.012 & 0.010 & 0.830 \\
\hline Female sex & -0.002 & -0.011 & 0.008 & 0.757 \\
\hline Gestational age (weeks) & 0.004 & 0.002 & 0.005 & $<0.001$ \\
\hline $\mathrm{pCO}_{2}$ on days 5-7 $(\mathrm{mmHg})$ & -0.005 & -0.005 & -0.004 & $<0.001$ \\
\hline \multicolumn{5}{|l|}{ Model 4 (Final model) } \\
\hline Cord blood $\mathrm{pH}$ & -0.131 & -0.210 & -0.052 & 0.001 \\
\hline Postnatal age (days) & -0.001 & -0.011 & 0.009 & 0.844 \\
\hline Female sex & -0.001 & -0.011 & 0.009 & 0.888 \\
\hline Gestational age (weeks) & 0.004 & 0.002 & 0.005 & $<0.001$ \\
\hline $\mathrm{pCO}_{2}$ on days 5-7 (mmHg) & -0.005 & -0.006 & -0.004 & $<0.001$ \\
\hline Lactate on days 5-7 $(\mathrm{mmol} / \mathrm{L})$ & -0.006 & -0.013 & 0.000 & 0.058 \\
\hline \multicolumn{5}{|l|}{ Model 5 (Additional model) } \\
\hline Cord blood $\mathrm{pH}$ & 0.016 & -0.003 & 0.035 & 0.092 \\
\hline Postnatal age (days) & 0.001 & -0.001 & 0.005 & 0.296 \\
\hline Female sex & 0.002 & -0.001 & 0.005 & 0.225 \\
\hline Gestational age (weeks) & 0.001 & 0.000 & 0.001 & 0.118 \\
\hline $\mathrm{pCO}_{2}$ on days 5-7 $(\mathrm{mmHg})$ & -0.009 & -0.010 & -0.008 & $<0.001$ \\
\hline Lactate on days 5-7 $(\mathrm{mmol} / \mathrm{L})$ & 0.001 & 0.000 & 0.003 & 0.149 \\
\hline $\mathrm{HCO}_{3}{ }^{-}$on days 5-7 $(\mathrm{mmol} / \mathrm{L})$ & 0.016 & 0.014 & 0.018 & $<0.001$ \\
\hline
\end{tabular}

2 Statistical significance was assumed for $p<0.05$ (indicated in bold). 